East African Medical Journal Vol. 77 No. 10 October 2000

CANCER OF THE PENIS AT KENYATTA NATIONAL HOSPITAL

G. A. O. Magoha, MBBS, FWACS, FICS, FMCS (Urol) and Z. W. W. Ngumi, MBChB, FFARCS, D.A., Department of Surgery, College of Health Sciences, University of Nairobi, P.O. Box 19676, Nairobi.

Request for reprints to: Professor G. A. O. Magoha, Department of Surgery, College of Health Sciences, University of Nairobi, P.O. Box 19676, Nairobi.

\title{
CANCER OF THE PENIS AT KENYATTA NATIONAL HOSPITAL
}

\author{
G. A. O. MAGOHA and Z. W. W. NGUMI
}

\begin{abstract}
Objectives: To determine how common cancer of penis is in this locality compared to all other malignant tumours and urological malignancies, and to determine and comment on the various methods of treatment available at $\mathrm{KNH}$.

Design: A retrospective case study.

Setting: Kenyatta National Referral Hospital, Nairobi.

Subjects: All patients with histologically confirmed cancer of penis at the Kenyatta National hospital between January 1970 and December 1999.

Results: There were 55 patients with penile cancer representing $0.1 \%$ of all malignancies during the study period. The mean age was 47.9 years with a peak incidence between 40-61 year age groups. Penile cancer was the most rare urological tumour representing $5.1 \%$. The most common was prostate cancer $(\mathbf{5 6 . 0 \%})$, followed by bladder cancer $(\mathbf{2 5 . 0 \%})$, kidney cancer $(7.9 \%)$, and testicular cancer $(6.1 \%)$. Thirty eight patients $(69.1 \%)$ presented with advanced disease, Jacksons stages III and IV. The majority $(96.4 \%)$ of the patients had glandular and preputial involvement. Histologically, $56.4 \%$ had well differentiated squamous cell carcinoma, $(23.6 \%)$ had moderately differentiated and $(20.0 \%)$ had undifferentiated carcinoma. Forty patients $(\mathbf{7 2 . 7 \%})$ were circumcised, nine patients $(16.4 \%)$ were circumcised as adolescents and three patients $(5.5 \%)$ circumcised as adults. Twenty five patients had partial penectomy with radiotherapy and or chemotherapy. Eight patients had total penectomy and radiotherapy while four patients had local excision and radiotherapy. Eleven other patients had radiotherapy either alone or combined with chemotherapy. Two patients had circumcision only and inguinal lymphadenectomy was effected on five patients after penectomy and radiotherapy.

Conclusion: Penile cancer is rare and the least common urological malignancy in this locality. It occurs in younger men with a mean age of 47.9 years, and presents as advanced Jackson's stages III and IV disease. The majority of patients had penectomy and local excision followed by radiotherapy.
\end{abstract}

\section{INTRODUCTION}

Squamous cell carcinoma of the penis accounts for two to five per cent of genitourinary malignancies(1). The incidence varies widely according to geographic distribution(2) and with hygienic standards, religious and various cultural practices among different communities from different parts of the world(3). In the western world, penile cancer is a rare condition accounting for less than one per cent of all male malignancies in the United States of America and Europe, but is much more common among some uncircumcised African, Asian, South American and tropical tribes where it constitutes a serious health hazard(4). Reddy et al(5) have reported that penile cancer occurs in $16.67 \%$ of all cancers in some parts of India, while in Brazil the incidence varies from 2.1-17\% of all cancers(6). In South Africa, the incidence among the African population varies between two per cent in Transvaal(7) and seven per cent in Natal(8). In most parts of Uganda, cancer of the penis was reported to be the commonest malignancy in the male adult African accounting for $12.2 \%$ of all cancers and second only to malignant lymphoma and cancer of the cervix $(9,10)$. The annual Medical report for Uganda recorded 124 new penile cancer cases in 1964, and Kyalwazi in Kampala in 1966(11) and Kyalwazi and Bhana in 1972(12) reported the Mulago hospital annual admission rate of seventeen to twenty two new cases per year. However, Williams compiled a cancer register for the West Nile district of Uganda where people do not practice ritual circumcision and reported penile cancer in eleven of 317 malignancies representing only $3.47 \%(13)$. Elshleman at Shirati Hospital in the Mara region of neighbouring Tanzania, also reported penile cancer in $4 \%$ of the 279 malignant tumours he reviewed (14). In Kenya inhabited by the uncircumcised Luo and the Turkana, penile cancer was previously reported to be rare(15).

Penile cancer is virtually unknown in the Jewish population where neonatal circumcision is routinely practised(16). The tumour typically occurs in men in the 
sixth or seventh decades of life, but is not uncommon in men below 40 years of age $(17,18)$, and has also been reported in children(19). Racial predilection has not been clearly proven and any observed racial differences are more likely to be due to socio-economic or environmental factors(20).

It is against this background that this study involving all patients diagnosed with cancer of the penis at the Kenyatta National referral and University of Nairobi teaching hospital over 30 years was carried out. The study determines how common cancer of the penis is in this locality, and the various treatment methods available.

\section{MATERIALS AND METHODS}

This was a retrospective study involving fifty five patients. All patients who were treated at the Kenyatta National Hospital over a 30 year period (1970-1999) with histopathologically confirmed diagnosis of penile cancer were included in this study. Sources of information included Urology and Radiotherapy clinics, operating theatre records, the histopathology department, the cancer registry and the surgical and radiotherapy wards of Kenyatta National Hospital. The patient case notes were retrieved from the Medical records department and all the necessary information such as the age, clinical presentation, stage of tumour, histological confirmation of cancer, the degree of differentiation, circumcision status and the type of treatment offered etc was retrieved and tabulated as shown under the results. For comparison all cases of other malignancies admitted to Kenyatta National Hospital over the same period was also obtained. For the period of 1990-1999, all Urological malignancies were obtained from the medical records department and compared to penile cancer. All these data were analysed and tabulated .

\section{RESULTS}

Fifty five patients with histologically proven cancer of penis were seen and treated at Kenyatta National Hospital over a 30 year period from January 1970 to
December 1999. The distribution of penile cancer by decade and its comparison with all other malignant tumours is illustrated in Table 1, and indicates that cancer of penis represents only $0.1 \%$ of all malignant tumours. The age range was 20-80 years with a mean of 47.9 years and a peak in the 41-60 year age group as depicted in Table 2.

Table 1

Comparison of penile cancer to all other malignancies at KNH over three decades (1970 - 1999)

\begin{tabular}{lccc}
\hline Decade & Total no of cancers & Cancer of penis & $\%$ \\
\hline 1st decade 1970-1979 & 10,677 & 12 & 0.1 \\
2nd decade 1980-1989 & 18,543 & 17 & 0.1 \\
3rd decade 1990-1999 & 22,796 & 26 & 0.1 \\
\hline Total 1970-1999 & 52,016 & 55 & 0.1 \\
\hline
\end{tabular}

Cancer of penis compared to other urological malignancies at $\mathrm{KNH}$ over a ten-year period is illustrated in Table 3, indicating that cancer of penis was the least common tumour representing $5.1 \%$ of total. The most common urological malignancy was prostate cancer accounting for $56.0 \%$, followed by bladder cancer $25.0 \%$, kidney cancer $7.9 \%$ and testicular cancer $6.1 \%$.

The anatomical distribution of tumour indicates 52 patients $(94.6 \%)$ had glandular cancer either restricted or spreading to the penile shaft or prepuce. Cancer was restricted to the prepuce alone in seven patients (12.7\%) and penile shaft alone in only three patients $(5.5 \%)$ as depicted in Table 4. The histological types of tumour are illustrated in Table 5, which indicates that the majority (56.4\%) were well differentiated squamous cell carcinoma. Thirty eight patients had advanced disease (Jackson's stages III and IV) as shown in Table 5.

Table 2

Age variation in penile cancer compared to other urological malignancies

\begin{tabular}{|c|c|c|c|c|c|}
\hline Age group in yrs & Penile cancer & Prostrate cancer & Bladder cancer & Kidney cancer & Testicular cancer \\
\hline $0-20$ yrs & 1 & 0 & 0 & 1 & 2 \\
\hline $21-30 \mathrm{yrs}$ & 2 & 0 & 4 & 7 & 9 \\
\hline $31-40 \mathrm{yrs}$ & 4 & 0 & 17 & 6 & 12 \\
\hline $41-50 \mathrm{yrs}$ & 7 & 3 & 32 & 7 & 4 \\
\hline $51-60 \mathrm{yrs}$ & 6 & 50 & 29 & 9 & 2 \\
\hline $61-70 \mathrm{yrs}$ & 4 & 106 & 26 & 7 & 1 \\
\hline $71-80 \mathrm{yrs}$ & 2 & 94 & 11 & 2 & 1 \\
\hline $81-90$ yrs & 0 & 32 & 8 & 1 & 0 \\
\hline Total & 26 & 285 & 127 & 40 & 31 \\
\hline
\end{tabular}


Table 3

Comparison of penile cancer with other urological cancers at KNH (1990-1999)

\begin{tabular}{lcc}
\hline Type of cancer & No. of patients & $\%$ of total \\
\hline Cancer of prostate & 285 & 56.0 \\
Cancer of bladder & 127 & 24.9 \\
Cancer of kidney & 40 & 7.9 \\
Cancer of testis & 31 & 6.1 \\
Cancer of penis & 26 & 5.1 \\
\hline Total & 509 & 100 \\
\hline
\end{tabular}

Table 4

Anatomical distribution in penile cancer patients at KNH (19701999)

\begin{tabular}{lcc}
\hline Site of primary lesion & No of patients & $\%$ of total \\
\hline Glans penis & 24 & 43.6 \\
Glans and shaft of penis & 12 & 21.8 \\
Prepuce only & 7 & 12.7 \\
Glans and prepuce & 4 & 7.3 \\
Shaft and prepuce & 3 & 5.5 \\
Shaft of penis & 3 & 5.5 \\
Whole penis and scrotum & 2 & 3.6 \\
\hline Total & 55 & 100 \\
\hline
\end{tabular}

Table 5

Clinical stage of penile cancer patients at KNH (1970-1999)

\begin{tabular}{lcc}
\hline Jacksons classification stage & No. of patients & $\%$ of total \\
\hline I & 10 & 18.2 \\
II & 7 & 12.7 \\
III & 28 & 50.9 \\
VI & 10 & 18.2 \\
\hline
\end{tabular}

Table 6

Histological types of penile cancer at KNH over three decades (19701999)

\begin{tabular}{lcc}
\hline Histological type & No. of patients & $\%$ of total \\
\hline $\begin{array}{l}\text { Well differentiated squamous cell } \\
\text { carcinoma }\end{array}$ & 31 & 56.4 \\
$\begin{array}{l}\text { Moderately differentiated } \\
\text { squamous cell carcinoma }\end{array}$ & 13 & 23.6 \\
$\begin{array}{l}\text { Undifferentiated (anaplastic) } \\
\text { squamous cell carcinoma }\end{array}$ & 11 & 20.0 \\
\hline Total & 55 & 100.0 \\
\hline
\end{tabular}

Table 7

Circumcision status in penile cancer patients at KNH (1990-1999)

\begin{tabular}{|c|c|c|}
\hline Circumcision status & No of patients & $\%$ of total \\
\hline Uncircumcised & 40 & 72.7 \\
\hline Circumcised as neonates & 0 & 0 \\
\hline Circumcision status unknown & 3 & 5.5 \\
\hline \multicolumn{3}{|c|}{ Total circumcised as adults, adolescents } \\
\hline and infants & 12 & 21.8 \\
\hline Grand total & 55 & 100.0 \\
\hline
\end{tabular}

Table 8

Methods of treatment in penile cancer patients at KNH (1970-1999)

\begin{tabular}{lrr}
\hline Type of treatment & & \\
\hline Circumcision & 2 & 3.6 \\
Local excision and radiotherapy & 4 & 7.3 \\
Partial penectomy and radiotherapy & 16 & 20.1 \\
Partial penectomy and chemotherapy & 3 & 5.5 \\
Partial penectomy, radiotherapy and chemotherapy & 6 & 10.9 \\
Total penectomy and radiotherapy & 8 & 14.5 \\
Radiotherapy alone & 5 & 9.1 \\
Chemotherapy and radiotherapy & 6 & 10.9 \\
No definitive treatment & 5 & 9.1 \\
& & \\
\hline Total & 55 & 100.00
\end{tabular}

Table 7 shows that 40 patients $(72.7 \%)$ were uncircumcised, 12 patients $(21.8 \%)$ were circumcised either in adolescence or as adults. No patient was circumcised in infancy and circumcision status was unknown (not recorded) in three patients $(5.5 \%)$. The various-methods of treatment are illustrated in Table 8.

\section{DISCUSION}

The findings in this study of penile cancer in only $0.1 \%$ of all malignancies treated at the National Hospital over 30 years indicate that the tumour is rare with a yearly average of about two patients despite the inclusion of the uncircumcised Kenyan tribes such as the Luo and Turkana in the study group. Cancer of the penis accounted for only $5.1 \%$ of all urological malignancies over a ten year period. The commonest urological tumour was cancer of the prostate representing $56.0 \%$. This is in direct contrast with the findings of Kyalwazi in Uganda who reported a yearly admission rate of 17-22 of penile cancer at Mulago hospital cases among the Baganda who do not routinely circumcise(11). Earlier reports from most parts of Uganda $(9,10)$ also reported it as common accounting for $12.2 \%$ of all cancers. The finding of rare penile cancer in this study conducted in Nairobi could be due to the fact that Nairobi metropolis is surrounded by the Kikuyu, Kamba and Maasai tribes who circumcise routinely. However, penile cancer is not uniformly common in Uganda where 
Williams reported its presence in only $3.5 \%$ of all malignant tumours reviewed from the West Nile district of Uganda where ritual circumcision is not practised(13). Furthermore, Elshleman also reported penile cancer in only $4.0 \%$ of all malignant tumours reviewed at Shirati hospital in northern Tanzania(14). Burkitt in 1965 reported cancer of the penis to be uniformly rare in some uncircumcised Ugandan tribes such as the Acholi and the Lugbara and some tribes of the southern highlands of Tanzania $(21,22)$.

The age range was $20-80$ years with a mean of 47.9 years and a peak incidence in the 41-60 year age groups similar to the findings of Bhana and Kyalwazi in Uganda in 1972 who reported a mean age of 46.5 years with a peak in the 41-60 year age group(12). It is however widely reported that squamous cell cancer of the penis is commoner in men in their sixth and seventh decades with an abrupt increase in incidence at 60 years and peaking at 80 years of age(23). In two such studies the mean age was reported as being 55 and 58 years $(24,25)$ respectively. The reason for the reported lower mean age and peak incidence of this cancer in East Africans is not clear and needs to be investigated further.

Cancer of the penis is usually an epidermoid tumour arising from the glans penis or the mucosal lining of the prepuce(26). In this study, the majority of cancers $(96.4 \%)$ had glandular and/or preputial involvement. Only three patients $(5.5 \%)$ had penile shaft tumours without the involvement of the glans and prepuce as shown in Table 4. The majority of patients $(69.1 \%)$, presented with advanced disease (Jackson's stages III and IV) with operable or inoperable inguinal metastases, and tumours involving adjacent structures or distant metastases(27). The reason for this late presentation of penile cancer in this locality is due to the delay in seeking appropriate medical advice as a result of socio-cultural taboos and ignorance.

The majority of patients $(72.7 \%)$ in this study were uncircumcised. This is in conformity with numerous previous reports that indicate penile cancer to be common among the uncircumcised males $(9-12,16)$. The development of tumour in the uncircumcised men has been attributed to the chronic irritative effects of smegma, a byproduct of bacterial action on desquamated cells that are within the preputial sac. Such exposure is accentuated by phimosis which is present in 25$75 \%$ of patients in most large series $(28,29)$. Although definitive evidence that smegma is a carcinogen has not been established, its relationship with penile cancer has been widely reported(30,31). Neonatal circumcision as practised by the Jews is known to prevent the development of cancer of penis(32,33). However, circumcision in adolescence and in adults does not prevent the development of penile cancer $(34,35)$. This is further buttressed by the findings in this study of penile cancer in twelve circumcised patients representing $21.8 \%$ of total as shown in Table 7. Nine of these patients $(16.4 \%)$ were circumcised during their adolescence while three patients $(5.5 \%)$ were circumcised as adults.

The earlier research on penile cancer research in East Africans was carried out in Uganda which was the seat of the premier and only medical school in the region at the time, incorporating the Mulago Hospital and located at Makerere in Kampala(9-13,36,37). These early investigators were faced with limited options in the management of penile cancer as radiotherapy was not available in Uganda at that time. They therefore offered surgical modes of treatment such as circumcision, partial or total amputation of penis with or without inguinal lymph node dissection and cytotoxic chemotherapy either alone or in addition to the various methods of surgery(1113,38). Radiotherapy was introduced in Kenya in 1968 through the collaboration of the Swedish government and the Karolinska Institute of Stockholm. As a result of this the majority of penile cancer patients treated at Kenyatta National Hospital between 1970-1999 benefited from radiotherapy treatment either alone, or in combination with surgery or chemotherapy as detailed in Table 8.

In this study only two patients $(3.6 \%)$ with early preputial cancer were treated with circumcision alone. Circumcision alone is usually followed by a high rate of tumour recurrence in upto $32 \%$ of the cases as reported by McDoughal(39). A total of 25 patients (45.5\%) had partial penectomy as a form of treatment. Sixteen of these patients $(20.1 \%)$ had additional external radiotherapy treatment, while another six patients $(10.9 \%)$ had both external radiotherapy and chemotherapy in addition to partial penectomy. The last three patients $(5.5 \%)$ in this group had partial penectomy and chemotherapy. For lesions involving the glans and the distal shaft of penis, even when apparently superficial, partial penectomy with a $2 \mathrm{~cm}$ margin proximal to the tumour is necessary to minimise local recurrence(40). The residual penile stump after partial penectomy is serviceable for upright micturition and satisfactory sexual function. Four patients $(7.3 \%)$ who declined both forms of penectomy had local tumour excision and radiotherapy. Total penectomy was performed on eight patients $(14.5 \%)$ followed by external radiotherapy. When penile cancer is extending to and involving the penile shaft so that partial penectomy does not provide a $2 \mathrm{~cm}$ tumour free margin, total penectomy and a perineal urethrotomy is advocated. This procedure allows the patient to void in the sitting position(2).

Five patients $(9.1 \%)$ were treated with external radiotherapy only. Two of these patients had refused any form of surgical treatment while the other three patients had disseminated disease. Radiotherapy, either external or brachitherapy (surface moulds or interstitial implantation) allows the preservation of penile structure and function in carefully selected patients(41). Small superficial tumours respond well to radiotherapy although squamous cell cancer is known to be characteristically radioresistant. The use of radiotherapy in the treatment of large invasive penile malignancies is less successful, requires higher radiation doses and may result in severe local complications such as urethral fistula, stricture or stenosis with or without penile pain and oedema, and radionecrosis of the penis $(42,43)$. Testicular damage and the development of secondary penile neoplasia has also been reported(44). Six other patients 
were treated with radiotherapy and chemotherapy. Chemotherapy has been utilised in the treatment of advanced penile cancer either alone or in combination with surgery or radiotherapy. Bleomycin, cisplastin and methotrexate are the most effective but complete responses are rare(45). Inguinal lymphadenectomy was effected on five patients after penectomy and radiotherapy. The overall prognosis in all stages of penile cancer is known to depend largely upon the presence or absence of inguinal lymph node metastases(46). Only supportive analgesic, haematinic and antibiotic treatment was given to the five patients who had advanced terminal disease.

Recent advances in surgical therapy including MOHS micrographic surgery, laser therapy and reconstructive surgery can provide satisfactory surgical treatment while minimising functional loss of the penis and avoiding the considerable complications associated with radiotherapy $(43,47,48)$.

\section{REFERENCES}

1. Thompson I.M. and Fair W.R. Penile carcinoma. AUA Update Serv. 1990; 9:1-8.

2. Lynch D.F. and Schellhamber P.L. Tumours of the penis: In: Walsh P.C; Retik A.B; Vaughan E.D. Jr and Wein A.J.(eds): Campbells Urology, 7th edition. PP. 2453-2485, Philadelphia W.B. Saunders Co. 1998.

3. Grabstald H. Cancer of the penis. J. Cont. Ed. Urol. 1979; 18: 15-19.

4. Gloeckler-Ries L.A., Hankey B.F. and Edwards (Eds). Cancer statistics review 1973-1987.In: National Cancer Institute, National Institute of Health Publication No. 90-2789, 1990, Bethseda, National Institute of Health.

5. Reddy C.R. R.M., Ragvaigah N.V. and Mouli K.C. Prevalence of carcinoma of the penis with special reference to India. Int. Surg. 1975; 60:470-476.

6. Brumini R. In cancer in Brazil: Histopathologica data 1976-1980. RIO de Janeiro, Ministry of Health 1982.

7. Higginson J. and Oettle A.G. Cancer incidence in Bantu and Cape coloured races of South Africa: Report of a cancer survey in Transvaal (1953-1955) J. Nat. Cancer Inst. 1960; 24:589-592.

8. Chapman D.S. Cancer of the penis: Study of 41 cases. Med. Proc. 1958; 814:817.

9. Dodge O.G. and Linsell C.A. Carcinoma of the penis in Uganda and Kenya Africans. Cancer 1963; 16:1255-1263.

10. Dodge O.G. Carcinoma of penis in East Africans. Brit J. Urol 1965; 37: 223 - 224.

11. Kyalwazi S.K. Carcinoma of the penis: A review of 153 patients admitted to Mulago Hospital Kampala Uganda. East. Afr. Med. J: 1966; 43:415-425.

12. Bhana D. And Kyalwazi S.K. Review of carcinoma of penis at Mulago. East Afr. Med. J. 1972; 49: 996-1001.

13. Williams E.H. A local cancer registry in a mission hospital in Uganda. East Afr. Med. J. 1966; 43:200-207.

14. Elshleman J.L. A study of the relative incidence of malignant tumours seen at Shirati Hospital in Tanzania. East Afr. Med. J. 1966; 43:273-283.

15. Magoha G.A.O. and Kaale R.FEpidemiological and clinical aspects of carcinoma of penis at Kenyatta National Hospital.East Afr. Med. J. 1995; 72:359-361.

16. Maden C; Sherman K.J. and Beckmann A.M. et al. History of circumcisions, medical conditions, sexual activity and risk of penile cancer. J. Nat. Cancer Inst. 1993; 16:1255-1257.

17. Ornellas A.A; Correria A.A. and Marota A. et alSurgical treatment of invasive squamous cell of the penis: Retrospective analysis of 350 cases. J. Urol. 1994; 151:1244-1248.

18. Horenblas A.A. and Van Titeren H. Squamous cell carcinoma of the penis IV: Prognostic factors of survival:analysis of tumour, nodes and metastasis classification system.J. Urol. 1994; 151:12391243.

19. Narasimharao K.L; Chterjee H. and Veliath A. J. Penile carcinoma in the first decade of life. Brit. J Urol. 1985; 57:358-361.
20. Loughlin K.R. Squamous cell carcinoma of the penis: Diagnosis and staging.In: Urologic Oncology; (eds) Osterling J. E. and Richie J.P first edition 1997 pp 591-593, Philadelphia, W. B. Saunders co.

21. Hutt M.S.R and Burkitt D. Geographical distribution of cancer in East Africa: A new clinicopathological approach. Brit. Med. J. 1965; 2719-720.

22. Burkitt D. P, Hutt M.S.R. and Slavin G. Clinicopathological studies of cancer distribution in Africa. Brit. J. Cancer 1968; 22:1-3.

23. Persky L. Epidemiology of cancer of penis. Rec. Results. Cancer. Res. 1977; 60:97-109.

24. Gursel E. O., Georgountzos C. and Uson A.C. et al. Penile cancer. Urology. 1973; 1:569-570.

25. Derrick F. C., Lynch K. M., Kretkowski R. C. and Yarbrough W. J. Epidermoid carcinoma of the penis: Computer analysis of 87 cases. J. Urol. 1973; 110:303-305.

26. Baez P. A. and Herrera J. R. Invasive carcinoma of the penis: Management and prognosis. In Osterling J. E. and Richie J. P. [eds.]; Urologic Oncology first edition 1997; pp 604-615, Philadelphia W. B. Saunders Co.

27. Jackson S. M. The treatment of carcinoma of the penis. Brit. J. Surg. 1966; 53:33.

28. Wolblast A. L. Circumcision and penile carcinoma. Lancet 1932; 1:150-153.

29. Marcial V. A., Figueroa J. and Marcial A. et al. Carcinoma of penis. Radiology 1962; 79:209-220.

30. Reddy D. and Baurah I. Carcinogenic action of human smegma. Arch. Pathol. 1963; 75:414-420.

31. Plaut A. and Kohn-Speger Carcinogenic action of smegma. Science. 1947; 195:391.

32. Leiter, E. and Lefkovitis A. M. Circumcision and penile carcinoma. N. Y State J. Med. 1975; 75:1520-1522.

33. Cochen M. and McCurdy S. Circumcision and the risk of cancer of the penis: A life table analysis. Amer. J. Dis. Child. 1980;134:484486.

34. Bissada N. K., Morcos Ror and EL-Senoussi, M. Post circumcision carcinoma of penis 1. Clinical aspects. J. Urol. 1986; 135:283-284.

35. Rogus B. J. Squamous cell carcinoma of penis in a young circumcised man. J. Urol. 1987; 138:861-862.

36. Davies J.N.P., Knowlden J. and Wilson B.A. Incidence rates of cancer in Kyadondo County Uganda 1954-1960. J. Nat. Cancer Inst. 1965; 35:789-792.

37. Templeton A. C. and Bianchi A. How much cancer is there in Uganda? An attempt at assessing the true frequency. East Afr. Med. J. 1972; 49:555-561.

38. Kyalwazi S.K. and Bhana D. Bleomycin in the treatment of cancer of penis. East Afr. Med. J. 1973; 50:331-337.

39. McDoughal W. S. Carcinoma of penis: Improved survival by early lymhadenectomy based on histological grade and depth of the primary lesion. J. Urol. 1995; 134:1364-1369.

40. Dekernion J. B., Tynbery P. and Persky L. et al. Carcinoma of the penis. Cancer 1973; 32:1256.

41. Kelley C.D., Arthur K., Rogoff E. and Grabstald H. Radiation therapy of penile. Urology 1974; 4:571-572.

42. McLean M., AKL A. M. and Warde P.et al. The results of primary radiation therapy in the management of squamous cell carcinoma of penis. J. Radiat. Oncol. Biol. Phys. 1993; 25:623-628.

43. Fukunga M., Yokoi K. and Miyazawa Y. et al. Penile verrucous carcinoma with anaplastic transformation following radiotherapy. A case report with human papilloma virus typing and flow cytometric DNA studies. Amer. J. Surg. Pathol 1994; 18:501-505.

44. Ravi R., Chatuverdy H. K. and Sastry D.V.L.N. Role of radiation therapy in the treatment of cancer of penis. Brit. J. Urol. 1994; 42:646-651.

45. Kattan J., Culine S. and Dros J. P et al. Penile cancer chemotherapy: Twelve years experience at Institute Gustave-Roussy. Urology $1993 ;$ 42:559-562.

46. Mukamel E. and deKernion J. B. Early verses delayed Iymph node dissection versus no lymph node dissection in carcinoma of the penis. Urol. Clin. North. Amer. 1987; 14:707-711.

47. Madej G., Douchez J. and Combs P.F. Cryosurgery of penile carcinoma: Short report of preliminary results. Oncology 1982; 39:350-352.

48. Mohs F. E., Snow S.N. and Larson P.O. Mohs micrographic surgery. Urol. Clin. North. Am. 1992; 19:291-304. 